\title{
CORRECTION
}

View Article Online

View Journal I View Issue

Check for updates

Cite this: RSC Adv., 2020, 10, 3992

rsc.li/rsc-advances

\section{Correction: Acridinedione as selective flouride ion chemosensor: a detailed spectroscopic and quantum mechanical investigation}

\author{
Nafees Iqbal, ${ }^{\text {a }}$ Syed Abid Ali, ${ }^{a}$ Iqra Munir, ${ }^{\text {a }}$ Saima Khan, ${ }^{\mathrm{b}}$ Khurshid Ayub, ${ }^{\mathrm{b}}$ Mariya al- \\ Rashida, ${ }^{C}$ Muhammad Islam, ${ }^{d}$ Zahid Shafiq, ${ }^{\text {dg }}$ Ralf Ludwig ${ }^{\text {ef }}$ and Abdul Hameed ${ }^{\star a}$ \\ Correction for 'Acridinedione as selective flouride ion chemosensor: a detailed spectroscopic and quantum \\ mechanical investigation' by Nafees Iqbal et al., RSC Adv., 2018, 8, 1993-2003.
}

The authors regret that the interpretation of the fluorescence spectra of compound $7 \mathbf{i}$ published in the original article was incorrect. In the original article, it was reported that upon excitation at $380 \mathrm{~nm}$, the fluorescence spectrum of compound $7 \mathbf{i}$ showed two emission bands at $450 \mathrm{~nm}$ and $770 \mathrm{~nm}$ (Fig. 5b of the original article). The signal at $770 \mathrm{~nm}$ (previously reported as an emission band), is instead a second order diffraction (an artefact of diffraction grating/spectrofluorometer monochromator), as revealed from the literature. ${ }^{\mathbf{1} 2}$ The authors thank a reader for highlighting this mistake.

The Royal Society of Chemistry apologises for these errors and any consequent inconvenience to authors and readers.

\section{References}

1 D. Tan, K. Sharafudeen, S. Zhou and J. Qiu, Nanoscale, 2012, 4, 6664.

2 J. R. Lakowicz, Principles of Fluorescence Spectroscopy, Springer, Berlin, 2006, p. 37.

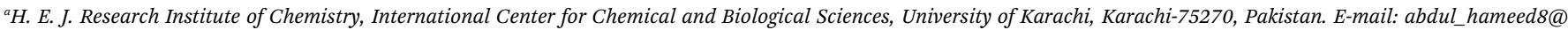
hotmail.com; Fax: +92-21-3481901; Tel: +92-21-99261701-2

${ }^{b}$ Department of Chemistry, COMSATS Institute of Information Technology, Abbottabad, KPK, Pakistan 22060

${ }^{c}$ Department of Chemistry, Forman Christian College, A Chartered University, Ferozepur Road, Lahore, Pakistan

${ }^{d}$ Institute of Chemical Sciences, Bahauddin Zakariya University, Multan, Pakistan

${ }^{e}$ Leibniz-Institut für Katalyse e. V. an der Universität Rostock, Albert-Einstein-Str. 29a, 18059 Rostock, Germany

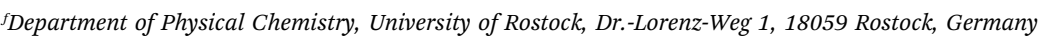

${ }^{g}$ Department of Chemistry, Quaid-i-Azam University, Islamabad 45320, Pakistan 